\title{
Risk management of water distribution system in Armenia
}

\author{
Artur Khachatryan* and Emil Khachatryan \\ National University of Architecture and Construction of Armenia, Yerevan, Armenia
}

\begin{abstract}
Risks in the water distribution system in the Armenian village of Noratus, have been assessed and treated following a risk management study based on the ISO 31 000:2009 standards, but extended for a strategic and long term level of analysis. The main goal is to ensure the safety of the whole water supply system. The brief description of the region as well as the current condition of the water supply system is given in order to clarify system features. The risk management here presented approach is now implemented in the Noratus network. Simulation have been performed using the AWARE-P software platform with the purpose of identifying critical components in the network and the asset probability of structural failure, as inputs for risk quantification. Then the risk magnitude is evaluated with the introduction of risk matrix. The phases of risk estimation and treatment are also carried out to propose the solutions for risk level reduction.
\end{abstract}

\section{Introduction}

Safety of water supply systems depends on a number of risk factors, risk sources, and hazards, that can take place or happen in different parts of the system, starting from the source of water until the tap of customers [15]. There is no generalized method which one can adopt to ensure the safety of the entire system, because each system is unique in itself. However, following the standardised risk management approach allows the application and adaptation of a general approach. In the case study, the risk assessment and treatment have been done in the water distribution system of Noratus village in Gegharkunik region (Republic of Armenia). The risk management in the water supply system has been not used in Republic of Armenia, that is why this article represents high importance in terms of one step for development of this methodology in water distribution systems (WDSs). As the Noratus has a typical distribution system which is also found in other parts of Armenia, it would be easy to apply this methodology later on to other systems which is a very valuable offshoot benefit of this paper. The common risk management process in water distribution systems (WDS) is described in order to understand and adopt the methodology for risk management in the system in Noratus. In this article it was decided to adopt the risk management process according to ISO 31 000:2009 standards in order to clarify the possible risk events for the system with the purpose to ensuring the safety in the WDS.

\footnotetext{
* Corresponding author: xachart90-90@ mail.ru
} 
Nowadays, there are different definitions for the risk in the literature [1,3], but one of the most important and widely used ones is based on this: the overall concept of risk is a combination of the probability of occurrence for the undesired event and the consequence of the event. These are usually proportional to each other[4,5,7]. To find the possible risk events in the system, it is important to clarify the following three principal questions

-What undesired events for the system can occur (Risk identification)?

-What is the probability of occurrence (Frequency analysis)?

-What will be the consequences (Consequence analysis)?

In order to conduct risk management for a system, it is important to follow some risk management standards, for instance, the widely accepted ISO 31000:2009 risk management principles, which has the following sequence of actions (Figure 1):

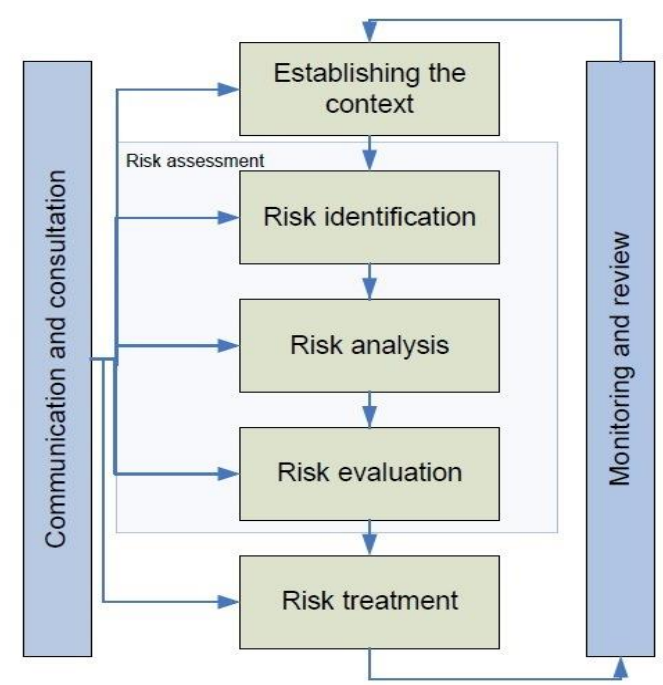

Fig. 1.Risk management (IEC60300-3-9).

\section{Methods}

Based on the context, the risks may be assessed in many ways. However, in order to simplify distinguishing methods between different risk assessment approaches, the risks are categorized as qualitative or quantitative and also semi-qualitative based on how it is expressed [9].

In the case study of Noratus WDS with accordance of available data, the focus was mainly on the semi-qualitative risk assessment, which is used in order to describe the relative risk scale. In this approach, different scales are used to characterize the likelihood of risk events and their consequences. Another criterion of decision is that during analysis of probability and consequences, this method does not require precise mathematical data and calculations. The number of risk levels can vary, in the case study for the Noratus WDS after discussions with water utility we accepted 5 risk levels.

For establishing the context, the description of the region and the current situation of water distribution systems in it have been provided. Risk identification has been implemented in order to find critical risk events for the systems. The main objective of a risk assessment of Noratus WDS is the evaluation of the identified risk event and suggestion of the risk reduction measures. 


\subsection{Risk Identification in Noratus water distribution system}

All risk events in the system are identified, clearly categorized and, based on the analysis of frequency and consequences of past events; the most crucial risk event of Noratus water distribution systems is identified as not delivering water to customers for extended periods of time creating impacts on different classes of consequences:

-Event 1- long period without water supply with economic impact

-Event 2- long period without water supply with service impact

-Event 3 - long period without water supply with health/life impact

The greatest threat for this risk events is distribution pipeline failures depending on importance of pipe for following system.

Studies indicate a range of pipeline failure mechanisms, which include structural breaks, joint failures, punctures, or corrosive failure of walls $[14 ; 10]$.

According to the frequency of causes for water main failure, one could rank the contributors as under [9]: materials and deterioration, weak joints, earth movement, freezing, internal corrosion, corrosive soils, construction or digging, stray direct current, seasonal changes in water temperature, heavy traffic, tidal influences, changes in system pressure, water hammer, and air entrapment. Information can be organized as clusters in respect of inventory attributes which are external condition threats such as corrosive soils, annual changes in water temperature, or the presence of corrosive materials. Other variables in the Noratus WDS can depend on pipeline history, for instance, poor construction, external conditions, internal and external corrosion, etc.

\subsection{Risk analysis in the Noratus water distribution system}

In order to clarify the probability and consequence of the defined risk events, it is important to define critical pipes in the system; these are pipes which failure is probable and can lead to serious risk for mentioned risk events .

\section{Probability of failure estimation}

The criticality analysis has been carried out using the AWARE-P software (http://baseform.org/np4/awareApp.htm). Mantioned softwate is designed for infrastructure asset management and planning of urban water systems with the aim to develop and implement in water utilities a structured procedure for infrastructure asset management [2]. Using this programme the component importance "CIMP"' analysis is implemented. The CIMP is expressed in terms of pipe importance in the system by comparing the system's demand, with all pipes operating, with the condition when that particular pipe is not operating. Component importance is computed for overall time steps of total simulation and its value varies between 0 (-all demand is satisfied over the simulation duration) and 1 (-no demand is satisfied at all over the simulation The output from the program is Hydraulic Critical Index ). The calculation of the satisfied demand (actual consumption) is based on two reference pressure values which are "Required Minimum Pressure" and "ZeroConsumption Pressure". These two pressure values accordingly representing the nodal pressure value above which nodal demand is fully satisfied and the one at which the node does not have any physical consumption, a linear interpolation is used for pressure values between the two limits. The calculation is based on the initially uploaded Epanet demanddriven hydraulic model of the system. 
Component importance analysis is launched with the respect to the existing pressure requirements for the WDSs in the Republic of Armenia (-Required Minimum Pressure of $60 \mathrm{~m}$ and Zero-Consumption Pressure of $30 \mathrm{~m}$ ).

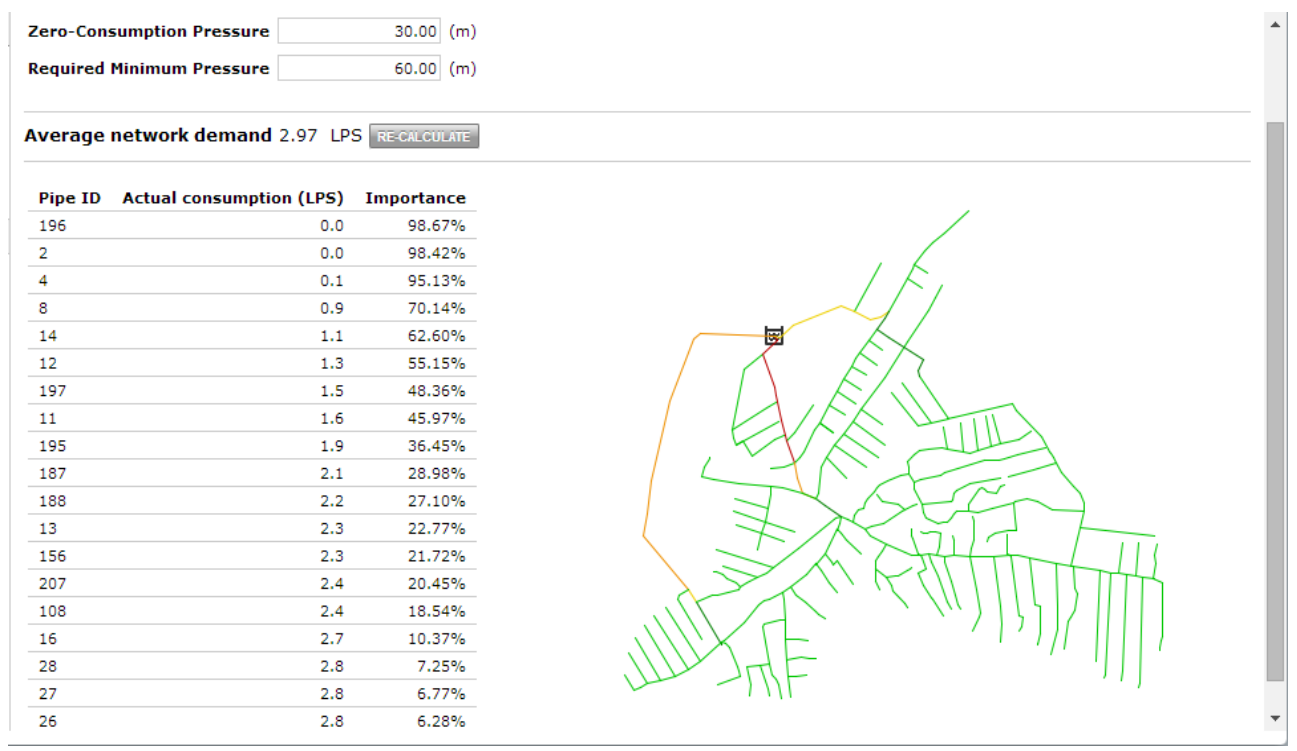

Fig. 2. Component Importance of Noratus WDS.

The component importance analysis is carried out (results in Fig 2) and the list of the most critical pipes with respect to supply reliability in the system are defined. In Fig 2, the pipes with their component importance in the network is shown, so for example the pipe with ID8 has $70.14 \%$ of importance,which means that its failure can cause serious problems to the system in terms of not delivering water to customers (- $70.14 \%$ dissatisfaction of the demand).

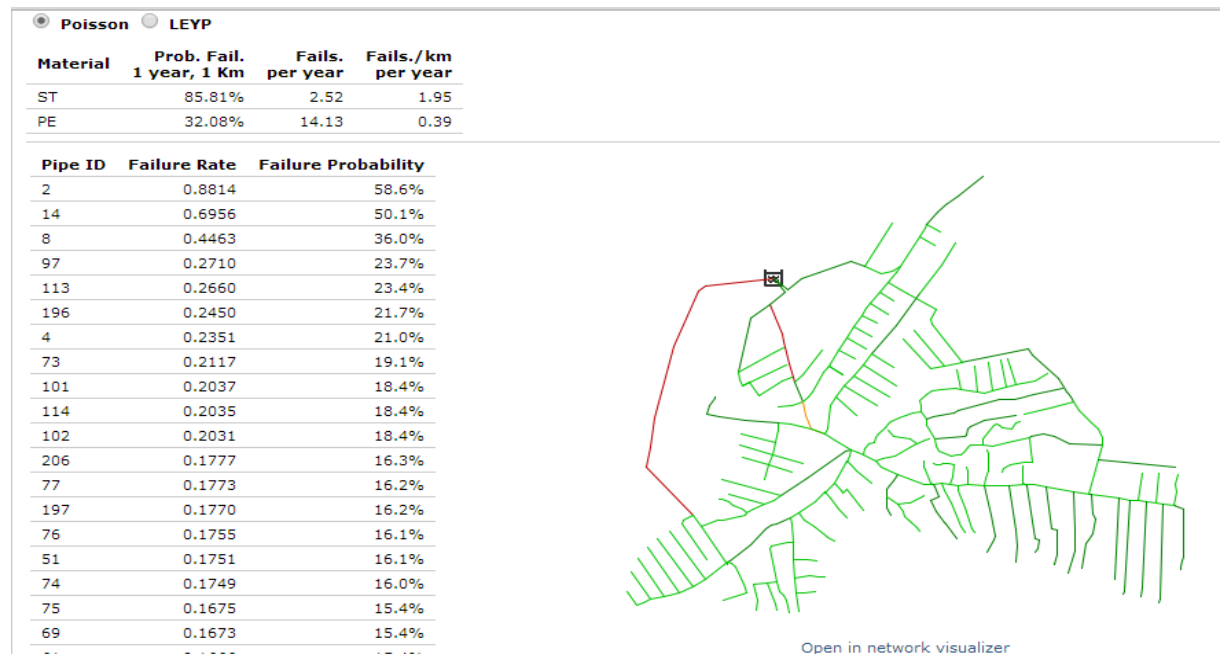

Fig. 3. Failure Analysis of Noratus WDS.

The analysis of structural failure of the network is also implemented (based on "Poisson model" http://baseform.org/np4/failTool.html) within the same software (AWARE-P) and 
the probability of pipe failure for given network is defined (Fig 3). The probability scale for the observed period with the scale for the Noratus network is sown in Table 1:

Table 1. The probability scale adopted for the risk event analysis.

\begin{tabular}{|c|c|c|}
\hline Levels & Likelihood description & Probability range \\
\hline 1 & Rare & $>1 \%$ and $\leq 5 \%$ \\
\hline 2 & Unlikely & $>5 \%$ and $\leq 10 \%$ \\
\hline 3 & Moderate & $>10 \%$ and $\leq 20 \%$ \\
\hline 4 & Likely & $>20 \%$ and $\leq 40 \%$ \\
\hline 5 & Almost certain & $>40 \%$ \\
\hline
\end{tabular}

\section{Consequence estimation}

For the total system, it is useful to have an indication of typical dimensions and an overall magnitude of consequence (Table 2), after that only to specify the consequences for mentioned system. The overall magnitude of consequence in WDSs can have 5 dimensions, as for agreement with the water utility, as it is described below (Table 3) (the consequences in WDS can vary according to the profile of the risk event, for each specific risk event the consequences dimensions should be defined according to system features).

Table 2. The ranking of consequence.

\begin{tabular}{|c|c|c|c|c|c|}
\hline levels & Health-Life & Environmental & Economical & Utility image & Service \\
\hline A & Range 1 & Range 1 & Range 1 & Range 1 & Range 1 \\
\hline B & Range 2 & Range 2 & Range 2 & Range 2 & Range 2 \\
\hline C & Range 3 & Range 3 & Range 3 & Range 3 & Range 3 \\
\hline D & Range 4 & Range 4 & Range 4 & Range 4 & Range 4 \\
\hline E & Range 5 & Range 5 & Range 5 & Range 5 & Range 5 \\
\hline
\end{tabular}


Table 3. The consequence in WDS.

\begin{tabular}{|c|c|c|c|c|}
\hline \multicolumn{5}{|c|}{ Consequence dimension } \\
\hline Range 1 & Range 2 & Range 3 & Range 4 & Range 5 \\
\hline $\begin{array}{c}\text { Insignificant } \\
\text { Consequence }\end{array}$ & $\begin{array}{c}\text { Minor } \\
\text { Consequen } \\
\text { ce }\end{array}$ & $\begin{array}{c}\text { Moderate } \\
\text { Consequence }\end{array}$ & $\begin{array}{c}\text { Major } \\
\text { Consequenc } \\
\text { e }\end{array}$ & $\begin{array}{c}\text { Catastrophic } \\
\text { Consequenc } \\
\text { e }\end{array}$ \\
\hline
\end{tabular}

\subsection{Risk evaluation}

The risk events evaluation is performed by adopting a risk matrix for risk events where the risk of identified events is expressed as a combination of likelihood/probability of occurrence and consequences of the event. According to the profile of the risk events in the Noratus water distribution system, three dimensions of consequence Health-Life, Economical and Service, were considered, as other consequences are negligible according to past events and discussions with the water utility. The image of the utility was considered to be unimportant, because the network is small and easy to operate. The water utility has fixed failures within 24 hours in the past, in keeping with Armenian government regulations. Loss of water would mean loss of embodied chemicals used for treatment and loss of embodied energy. These on the upstream can cause some environmental impacts. So we have to somehow compensate this loss by treating and pumping more water, which may be instrumental in causing GHG emissions on the upstream [13]. However, this effect is considered negligible due to small size of the village (it is better to consider for big cities with greater consumption and overall higher resulting GHG emissions). The risk is ranked using the matrix illustrated in Table 4. Risk is ranked using a matrix that has ranges of consequence and likelihood as the axes. The combination of a consequence and likelihood range gives an estimate of risk or a risk ranking. The risk matrix for this system is decided to have five by five grid of consequence (A-E) and likelihood (1-5) ranges. The construction of matrix and also the scale and placement of risk events is done with strong collaboration with water utility.

The risk prioritization has been done in respect of the importance components, Failure Analysis simulations and also with the collaboration of water utility of Noratus. The pipes with ID-2, 4, 14, 8 represent High risk for the network which means the brake of mentioned pipes can cause the serious risk for defined risk events(few pipes including ID-196; 197 under rehabilitation plan in the near future by water utility, that is why they are not mentioned as risky pipes for the system).

The risk for each event is defined as the probability of having long periods without water and economic, service, health/life consequence accordingly for Event 1,2,3 (Table 5).

For each event, calculation of the total risk is done (middle value is chosen for total value of risk events). For instance the pipe with ID-2 represents 5E-high risk for the network within three risk events dimensions, because it represents high importance for the system (component importance); probability of failure is high (failure analysis). For consequence side, the pipe ID-2 is located in the centre of the village under the main street (there are houses, school and hospital) and a breakage in this case, can cause serious "Health-Life" consequence (because of the pipe failure the pressure drop in the network can cause the incursion of contaminants into pipes), can cause serious "Health-Life" consequence (because of the pipe failure the pressure drop in the network can cause the incursion of contaminants into pipes), can cause serious "'Health-Life"' consequence (because of the pipe failure the pressure drop in the network can cause the incursion of contaminants into 
pipes),can cause serious "Health-Life" consequence (because of the pipe failure the pressure drop in the network can cause the incursion of contaminants into pipes), rehabilitation of pipe ID-2 is quite difficult and time-consuming because of heavy traffic (service) and expansive due to high quality asphalt cover on it (economical). So the pipe 2 has $58 \%$ probability of failure which means that failure is "Almost certain (5)", and consequences in all dimensions are defined as "Catastrophic (E)". The same evaluation approach for all prioritized pipes in addition close collaboration with water utility and some assumptions (with the respect of features in the area) have been made in order to acquire correctness as much as possible. The risk matrix for events will have the following shape (Figure 6).

Table 4. Risk ranking matrix.

\begin{tabular}{|c|c|c|c|c|c|c|c|}
\hline & \multicolumn{5}{|c|}{ Consequence } \\
\hline & & & \multirow{2}{*}{$\frac{\text { Insignificant }}{\mathrm{A}}$} & \multirow{2}{*}{$\begin{array}{c}\text { Minor } \\
\mathrm{B}\end{array}$} & \multirow{2}{*}{$\frac{\text { Moderate }}{\mathrm{C}}$} & \multirow{2}{*}{$\begin{array}{c}\text { Major } \\
\mathrm{D}\end{array}$} & \multirow{2}{*}{$\frac{\text { Catastrophic }}{\text { E }}$} \\
\hline & & & & & & & \\
\hline & 5 & $\begin{array}{l}\text { Almost } \\
\text { certain }\end{array}$ & $\begin{array}{c}\text { 5A- } \\
\text { Moderate }\end{array}$ & $\begin{array}{c}\text { 5B- } \\
\text { Moderate }\end{array}$ & 5C- High & 5D- High & 5E- High \\
\hline \multirow{4}{*}{ 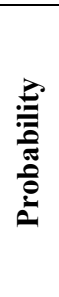 } & 4 & Likely & $\begin{array}{c}4 \mathrm{~A}- \\
\text { Moderate }\end{array}$ & $\begin{array}{c}\text { 4B- } \\
\text { Moderate }\end{array}$ & $\begin{array}{c}4 \mathrm{C}- \\
\text { Moderate }\end{array}$ & 4D-High & 4E- High \\
\hline & 3 & Moderate & 3A-Low & $\begin{array}{c}\text { 3B- } \\
\text { Moderate }\end{array}$ & $\begin{array}{c}3 \mathrm{C}- \\
\text { Moderate }\end{array}$ & $\begin{array}{c}\text { 3D- } \\
\text { Moderate }\end{array}$ & 3E-High \\
\hline & 2 & Unlikely & 2A-Low & 2B-Low & $\begin{array}{c}2 \mathrm{C}- \\
\text { Moderate }\end{array}$ & $\begin{array}{c}\text { 2D- } \\
\text { Moderate }\end{array}$ & $\begin{array}{c}\text { 2E- } \\
\text { Moderate }\end{array}$ \\
\hline & 1 & Rare & 1A-Low & 1B-Low & 1C-Low & $\begin{array}{c}\text { 1D- } \\
\text { Moderate }\end{array}$ & $\begin{array}{c}\text { 1E- } \\
\text { Moderate }\end{array}$ \\
\hline
\end{tabular}

Table 5. The ranking of probability and consequence for each risk event.

\begin{tabular}{|c|c|c|c|}
\hline & Event 1 & Event 2 & Event 3 \\
\hline 2 & $5 \mathrm{E}$ & $5 \mathrm{E}$ & $5 \mathrm{E}$ \\
\hline 14 & $5 \mathrm{C}$ & $5 \mathrm{D}$ & $5 \mathrm{D}$ \\
\hline 4 & $4 \mathrm{D}$ & $4 \mathrm{D}$ & $4 \mathrm{C}$ \\
\hline 8 & $4 \mathrm{E}$ & $5 \mathrm{E}$ & $5 \mathrm{E}$ \\
\hline Total & $4.5 \mathrm{D}$ & $4.75 \mathrm{E}$ & $4.75 \mathrm{D}$ \\
\hline
\end{tabular}

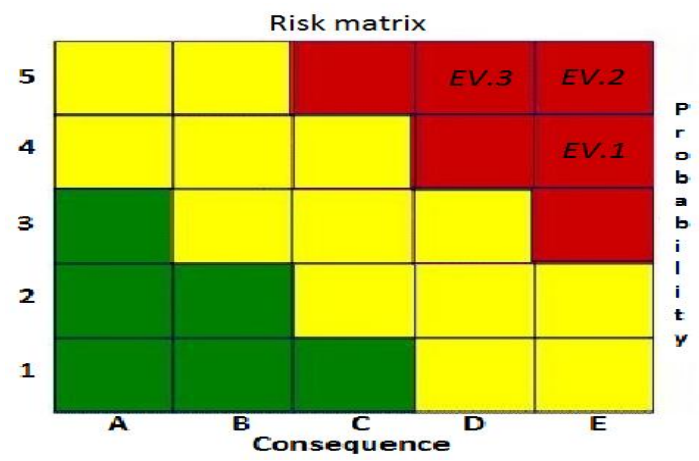

Fig. 4. Risk events evaluation matrix. 


\section{Results (Risk treatment)}

Risk treatment involves identification of possible measures for risk reduction. According to the risk assessment results and also after discussions with utility, the risk reduction measure for Noratus water distribution system consisted mainly on acting on reducing the probability side of the risk events by improving the system redundancy with an additional new pipe connections (PE110 pipes, ID 1 and ID 9) ; in addition it was planned to mitigate eventual economic consequences by rehabilitating the pipes ID-2;8;14 before restoration of asphalt cover in the following streets, in order to avoid extra charge for the asphalt.

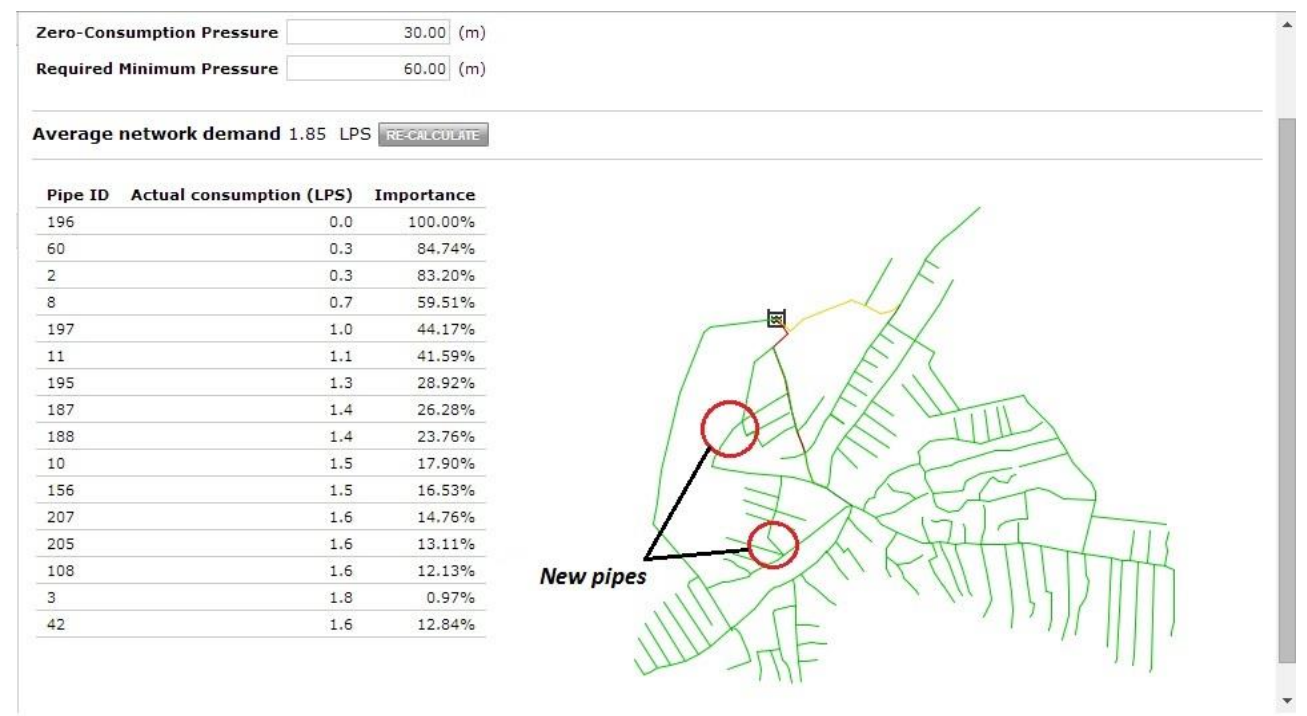

Fig. 5. Component Importance after risk treatment.

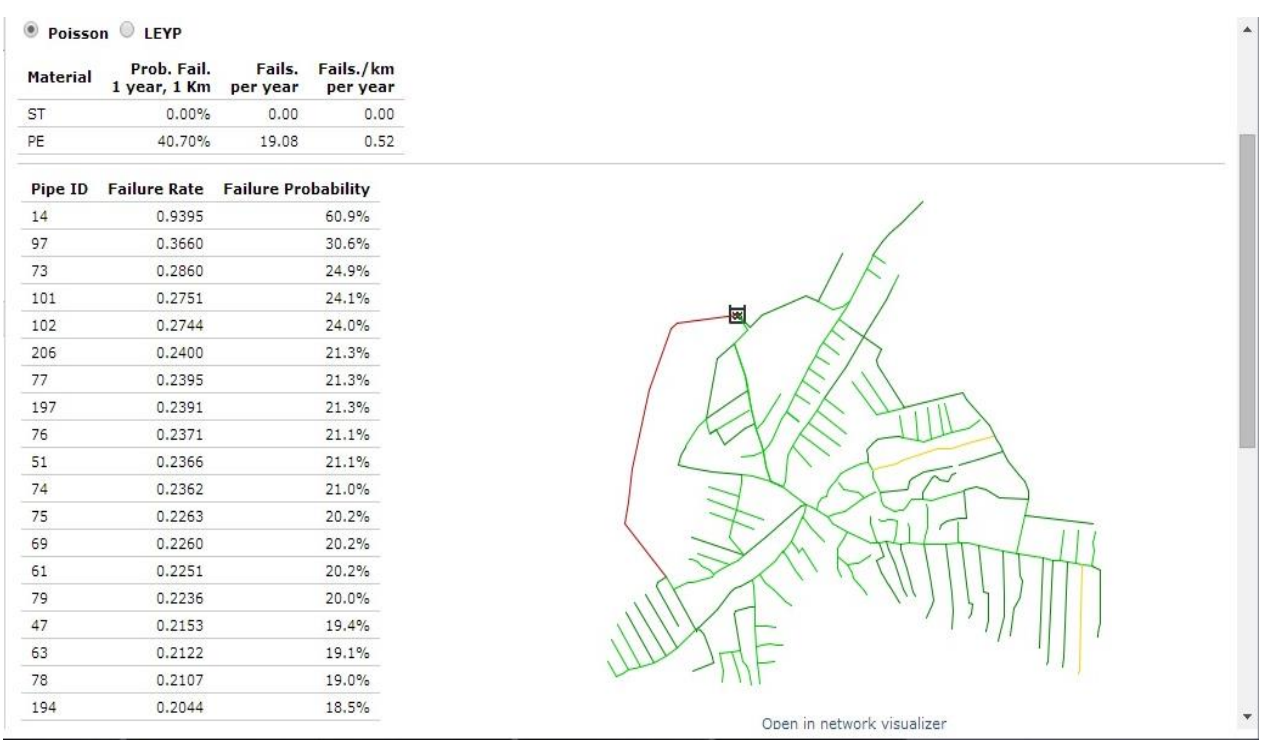

Fig. 6. Risk evaluation matrix after risk treatment. 
Adjusted system is analysed for component importance (Figure 5) and failure analysis (Figure 7). Slightly change in probability failure and component importance of pipes is observed (pipes ID-2;8;14 are considered as the new pipes, but still the pipe ID-14 has 60.9 $\%$ probability of failure according to simulation; the component importance simulation is claiming that the pipe ID-14 doesn't represent any importance for the system, it means the failure of it will not cause any serious consequences for the network). As it was revealed in simulation results for adjusted system, previously prioritized pipes do not representing risk for the risk events. New risk matrix is also shown in the figure 7. After the mentioned measures (including some extra rehabilitation works conducted by water utility) we can insure a reduced risk level for the water supply in Noratus village.

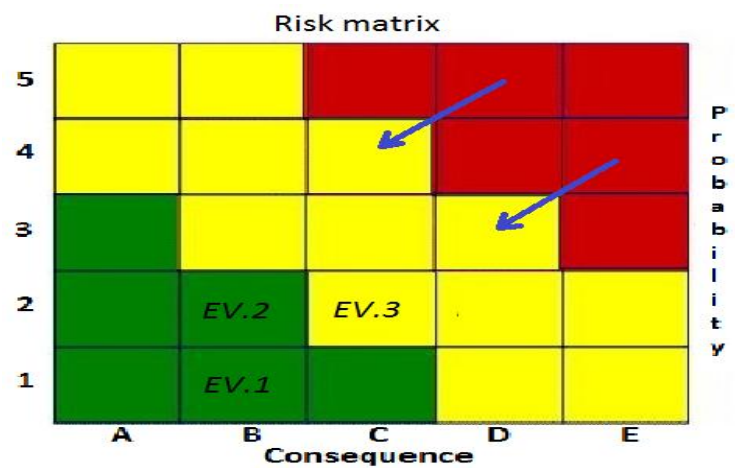

Fig. 7. Failure Analysis after risk treatment.

\section{Discussions}

In this article, the risk management methodology based on ISO 31000:2009 standards was used in order to identify, evaluate and treat the most critical risk events for Noratus water distribution system. The critical risk events for network were identified, that is not delivering water to customer for an extended period of time with defined impacts; pipes breaks is considered the relevant risk hazard and therefore a failure probability analysis based on past events has been performed. This is pretty new experience for Armenian villages, therefore we intend to develop this method for other communities.

\section{Conclusion}

For risk analysis, the Component Importance (AWARE-P) simulation was done with the purpose to identify critical pipes in the network as those that might be responsible of long period without supply in case of failure, and also the Failure Analysis was launched, so as to define the probability for those pipes to break. The risk estimation was implemented within three risk event dimensions; risk matrix for risk events was obtained. The risk treatment measures included new pipe connections and pipe rehabilitations, with the purpose to insure the safe and robust operation of the system and after these measures new treated risk matrix were shown.

The writers thank the personel of at the Noratus water utility for their kind support and for all data which have been used for this article. This work has been carried out in the frame of 'Creating the ways for sustainable urban, architectural and construction complexes development in RA and elaboration of directions with use of permanent monitoring systems' program. 


\section{References}

1. T. Aven. On some recent definitions and analysis frameworks for risk, vulnerability and resilience. J Risk Anal 31(4):515-522 (2011)

2. H. Alegre, S.T. Coelho, D. Covas, M.C. Almeida, M.A. Cardoso. Infrastructure Asset Management of Urban Water Systems. (book chapter) in "Water Supply System Analysis - Selected Topics", ed. Avi Ostfeld (ISBN 978-953-51-0889-4) (2013).

3. C. Huang. Integration degree of risk in terms of scene and application. StochEnv Res Risk Assess 23:473-484 (2009)

4. L. Huipeng. Hierarchical risk assessment of water supply systems. PhD Thesis, Loughborough University (2007)

5. J. Torres, K. Brumbelow, S. Guikema. Risk classification and uncertainty propagation for virtual water distribution systems. J ReliabEngSyst Safety 94(8):1259-1273 (2009)

6. ISO 31000:2009, Risk management - Principles and guidelines (2009).

7. S. Kaplan. The words of risk analysis. J Risk Anal 17(4): 407-417 (1997).

8. G. J. Kirmeyer, et al. "An assessment of water distribution systems and associated research needs." Publication 90658, Water Research Foundation and American Water Works Association, Denver. (1994).

9. Laura-Diana Radu Qualitative, Semi-Quantitative And, Quantitative Methods For Risk Assessment: Case Of The Financial Audit.Alexandru Ioan Cuza University, Faculty of Economics and Business Administration in its journal Analele Stiintifice ale Universitatii "Alexandru Ioan Cuza" din Iasi.pp 643-657 (2009).

10. D. K. O'Day, R. Weiss, S. Chiavari and D. Blair. Water main evaluation for rehabilitation/replacement, AWWA Research Foundation and Environmental Protection Agency, Denver. (1986).

11. L. Tuhovcak,, J. Ruka, T. Juhanak. Risk analysis of water distribution systems. Security of Water Supply Systems: from Source to TapNATO Security through Science Series Volume 8, pp 169-182 (2006).

12. L. Tuhovcak, J. Ruka. Strategic Asset Menegment of Water Supply and Wastewater Infrastructure IWA,pp 286-300 (2007).

13. G. Venkatesh: Cost-benefit analysis -leakage reduction by rehabilitating old water pipelines: Case study of Oslo (Norway), Urban Water Journal, 9:4, 277-286 (2012)

14. T. Walski and A. Pelliccia. "Economic analysis of water main breaks." J. Am. Water Works Assoc. 74 (3 ), p 140-147(1982)

15. (WHO) World Health Organization. http://www.who.int/en/ 